The Journal of Animal \& Plant Sciences, 30(6): 2020, Page: 1574-1578

ISSN (print): 1018-7081; ISSN (online): 2309-8694

\title{
BEAUVERIA PSEUDOBASSIANA REHNER AND HUMBER, 2011 A NEW ENTOMOPATHOGENIC FUNGUS FROM GARA MOUNTAIN, IRAQ
}

\author{
F. R. $\operatorname{Hassan}^{1 *}$, S. K. Abdullah ${ }^{2}$ and L. H.Assaf ${ }^{3}$ \\ ${ }^{1}$ Department of Plant Protection, College of Agricultural Engineering Sciences, University of Duhok, Kurdistan Region \\ - Iraq; ${ }^{2}$ Medical Laboratory Technology Department, Alnoor University College, Nineva, Iraq; ${ }^{3}$ General Directorate of \\ Agriculture-Duhok, Kurdistan Region - Iraq \\ *Corresponding author's email: feyroz.hassan@uod.ac
}

\begin{abstract}
There is a growing interest in the exploitation of naturally occurring entomopathogenic microorganisms for the control of pests. Beauveria spp is an important entomopathogenic fungi that used as a biocontrol agent of insect pests. The species Beauveria pseudobassiana Rehner and Humber, 2011 was isolated from soil samples collected from the hibernation site of sunn pest Eurygaster integriceps Puton (The most important insect attacks wheat plants in Iraq) at Gara Mountain, Iraq by using selective medium based on oat meal agar amended with CTAB and cyclohexamide. The isolated species was identified depending on both morphological characteristics and molecular data based on ITS-rDNA region. Using blast search, the sequences exhibited high sequence homology (99\%) to the fungus B. pseudobassiana that recorded for the first time in Iraq.
\end{abstract}

Keyword: Beauveria pseudobassiana, Iraq, Kurdistan region, new record.

https://doi.org/10.36899/JAPS.2020.6.0178

Published online August 03,2020

\section{INTRODUCTION}

The genus Beauveria Vuill. 1912 (Cordycipitaceae: Hypocreales) is a cosmopolitan entomopathogenic fungus recorded in various kinds of habitats and ecosystems including insects, soil and plants (Meyling and Eilenberg, 2007; Medo et al., 2016; Imoulan et al., 2017) and used for control of many species of insects related to different orders (Roy et al., 2010). The isolation of Beauveria species from soil are commonly based either on using Galleria bait method (larvae of Galleria mellonella L., 1758, Lepidoptera: Pyralidae), or by, the use of selective media (Meyling et al.,2009; Medo and Cagáń, 2011; Posadas et al.,2012). Recent phylogenetic studies indicated that Beauveria showed a lot of genetic diversity and a complex that consists of a number of cryptic species. Currently, there are totally 21 species included in the genus. Based on the recognition of 12 species by Rehner et al. (2011), i.e., $B$. bassiana, $B$. brongniartii, $B$. caledonica, $B$. amorpha, $B$. asiatica, $B$. australis, B. kipukae, B. pseudobassiana, $B$. varroae, $B$. sungii, $B$. malawiensis and $B$. vermiconia, some 9 more species have been described, these include, B. lii (Zhang et al., 2012), B. sinensis (Chen et al., 2013), B. rudraprayagi (Agrawal et al., 2014) and B. hoplocheli (Robène et al., 2015), B. gryllotalpidicola and $B$. loeiensis (Ariyawansa et al., 2015). B. medogensis (Imoulan et al., 2016b), B. locustipuila (Kepler et al., 2017) and B. majiangensis (Chen et al., 2018). Therefore, species differentiation using general phylogenetic markers as intergenic spacer (ITS) region of rDNA as DNA barcode has been successfully employed for discrimination of very closely related species (Rehner and Buckley, 2005; Tu and Krischner, 2014; Imoulan et al. 2016a). Several studies have revealed that $B$. pseudobassiana is a promising entomopathogen and might be used as a pesticide for controlling a wide spectrum of insects. Isolates from $B$. pseudobassiana have been reported to be virulent to pine weevil Pissodes nemorensis (Romon et al., 2017) and showed a high virulent against males and females of Monochamus galloprovincialis, the vector of pine wilt disease (Alvarez-Baz et al., 2015). In Turkey, Kocacevik (2015) showed the efficacy of $B$. pseudobassiana as a promising bicontrol agent against bark beetle dendroctonus micans (Coleoptera: Curculionidae) and used in Italy as a biological insecticide in protein bait sprays to control the Mediterranean fruit fly Ceratittis capitata (Bedini et al., 2018).

In Iraq and according to the previous studies of entomopathogenic fungi isolated from soils at Gara Mountain/ Iraq, Beauveria species were recorded as $B$. bassiana and B. brongniartii (Assaf, 2007; Assaf et al., 2011) but they were only identified depending on their morphological characteristics. More recently, B. varroae was identified based on morphological characteristics and the analysis of ITS-rDNA added to the genus in Iraq (Hassan et al., 2019). The present study aims to identify Beauveria isolates obtained from Gara mountain soils based on both morphological and molecular analysis. 


\section{MATERIALS AND METHODS}

Isolation: Soil samples (about $500 \mathrm{~g}$ each) were collected from a depth of $0-10 \mathrm{~cm}$ beneath surface litter under the plants that regards as most suitable hibernation sites for sunn pest from Gara Mountain (2066m above sea level,37.0111 $\left.{ }^{\circ} \mathrm{N}, 43.3670^{\circ} \mathrm{E}\right)$. Isolation method of Beauveria species from soil was described in details in Hassan et al. (2019). The medium used basically composed of oat meal agar amended with $0.6 \mathrm{~g} / \mathrm{l}$ cetyltrimethyl ammonium bromide (CTAB) as described by Pasadas et al. (2012) with a modification by addition of $0.25 \mathrm{~g} / 1$ cyclohexamide.

Morphological observation: To produce monosporic cultures, conidial suspension of $1 \times 10$ conidia/ ml were prepared from fungal cultures grown on PDA plates for two weeks. The single colony reproduced from single conidia was transferred into a new PDA dish and incubated at $25{ }^{\circ} \mathrm{C}$. Microscopic measurements of conidia were taken from slide-cultures produced by inoculation a small amount of mycelium on a drop of methylene blue stain and overlaid by a cover slip. Measurements were performed with graticule lens.

Genomic DNA extraction, PCR and sequencing: Establishment of monosporic cultures and microscopic measurements of conidia were mentioned in Hassan et al. (2019).The extraction was done according to a commercial animal and fungi DNA preparation kit protocol (Jena Bioscience, Germany).

Genomic DNA was used as template for PCR amplification of its stander for ITS region using universal primers ITS5/ITS4 (White et al., 1990). The PCR reactions were performed in a final volume of $50 \mu \mathrm{l}$ containing $25 \mu \mathrm{l} 2 \mathrm{x}$ Taq PCR Master Mix, $2 \mu 1$ of each reverse and forward primer $(20 \mathrm{pml}), 2 \mu \mathrm{l}$ of genomic DNA (30-100 ng/ $\mu \mathrm{l})$ and $19 \mu \mathrm{l}$ of RNase- Free water. Amplification was performed in a GeneAmp PCR System 9700 thermocycler (Applied Biosystems) according to a program as follow: $95 \mathrm{C}$ for $3 \mathrm{~min}$, followed by 35 cycles of $95^{\circ} \mathrm{C}$ for $30 \mathrm{~s}, 55^{\circ} \mathrm{C}$ for $30 \mathrm{~s}$, $72^{\circ} \mathrm{C}$ for $45 \mathrm{~s}$ and final extension step of $72^{\circ} \mathrm{C}$ for $10 \mathrm{~min}$.

Amplified PCR products were visualized by $1 \%$ agarose gel electrophoresis stained with $3 \mu \mathrm{l}$ of EvaGreen ${ }^{\circledR}$ Fluorescent Gel Stain (Jena Bioscience, Germany). The electrophoresis was done at $100 \mathrm{~V} / \mathrm{cm}$ gel a voltage source $(80 \mathrm{~V})$ for $40 \mathrm{~min}$., photography and visualization of bands were carried out using a transilluminator equipped with a digital camera.

Phylogentic and Data analysis: The resulting sequences were checked and aligned using BioEdit sequence alignment editor 7.0.0 (Isis Pharmaceuticals, Inc., Carlsbad, CA, USA). The similarity of the sequence with homologous sequences deposited in GenBank was calculated using the "BLAST" tool on the National Center for Biotechnology Information (NCBI) website. Alignment of selected sequences was done with clustalW. All sequences generated in this study were submitted to GenBank. The phylogenetic tree was constructed using the Neighbor-Joining method with Jukes-Cantor model in MEGA7. Branch support was estimated by bootstrap analysis with 1000 replicates.

\section{RESULTS}

Morphological observation: Based on microscopic observation, samples isolated from Gara Mountain soil display the typical morphological characteristics found in species of Beauveria that described elsewhere (Rehner et al., 2005). The colonies had the appearance of dense clusters of globose spherical conidiogenous cells, with apical denticulate rachis, which give them a zigzag appearance giving rise to sessile, hyaline smooth conidia.

Sequencing of ITS and phylogenetic analysis: The results of rDNA-ITS sequencing of the Beauveria isolates showed $600 \mathrm{bp}$ of special DNA fragments sequenced.

Using BLAST search, to compare the resulting sequences with sequences of rDNA accessed in Genbank, phylogentic analysis showed that the obtained sequences shares 99\% homology to Beauveria pseudobassiana strains: Turkish isolates (MH185843, MH185848, MH185847, MH259852, MH185849, MH185845) and Mexico isolates ( KC355187 and KC355186) (Figure 1). Together, morphological identification and molecular identification showed that Beauveria isolate is Beauveria pseudobassiana (Genbank accession No. MH374534).

\section{Taxonomy}

Description of Beauveria pseudobassiana as a new record for Iraq: Beauveria pseudobassiana S.A. Rehner and R.A. Humber, Mycologia 103: 1068(2011) (Fig.2:14).

Colony growth and appearance on potato dextrose agar attaining a diameter of $28 \mathrm{~mm}$ after 10 days at $25^{\circ} \mathrm{C}$. Surface mycelium velutinous to cottony, closely appressed to agar surface; margin white with colony interior white or changing to yellowish white (Figure. 2) to pale yellow. Conidia aggregated as spherical clusters, white in mass. Colony reverses either uncolored or yellowish white. Vegetative hyphae septate, branched, hyaline, smooth-walled, 1-2.2 $\mu \mathrm{m}$ wide. Conidiogenous cells solitary but usually in dense lateral clusters, base subspherical to ampulliform and 3-6 $\mu \mathrm{m}$ wide. Conidia $2-2.5 \times 1.3-2.2 \mu \mathrm{m}$, primarily subglobose or broadly ellipsoid, hyaline, aseptate, walls thin and smooth. 


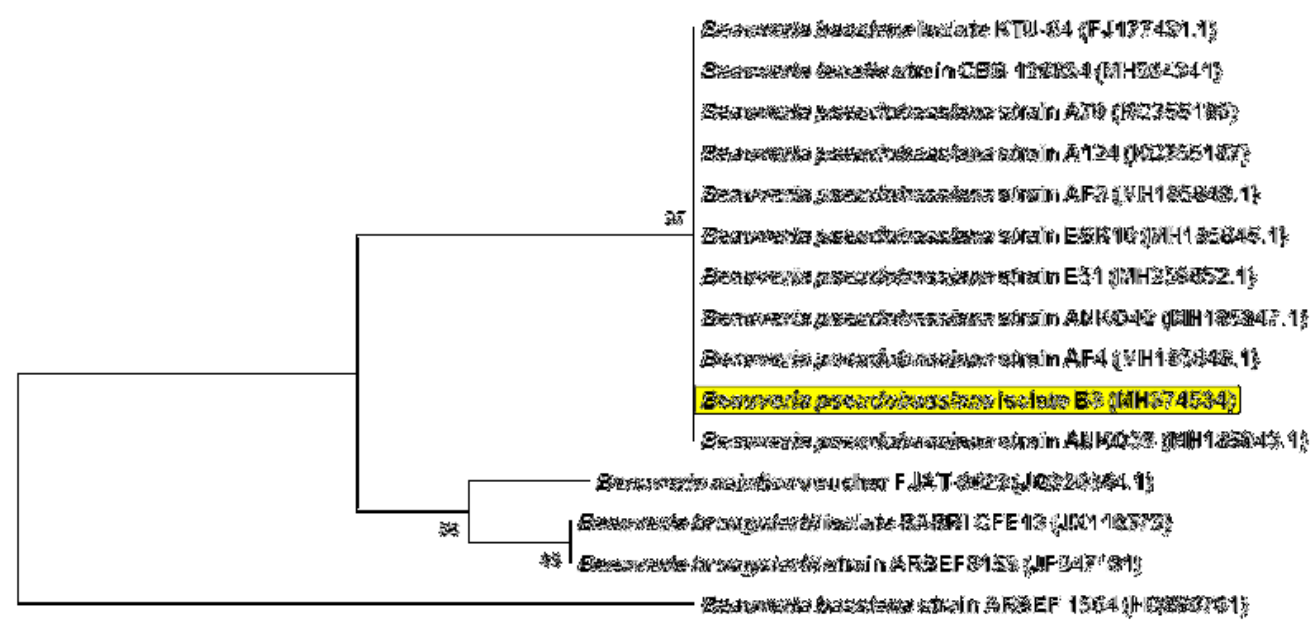

Figure 1.Phylogenetic tree of Beauveria pseudobassiana based on Neighbor-Joining analysis with 1000 bootstrap replicates of ITS-rDNA sequences of the new strain from Iraq (in yellow) and related Beauveria species from GenBank. GenBank accession numbers provided behind the species names.

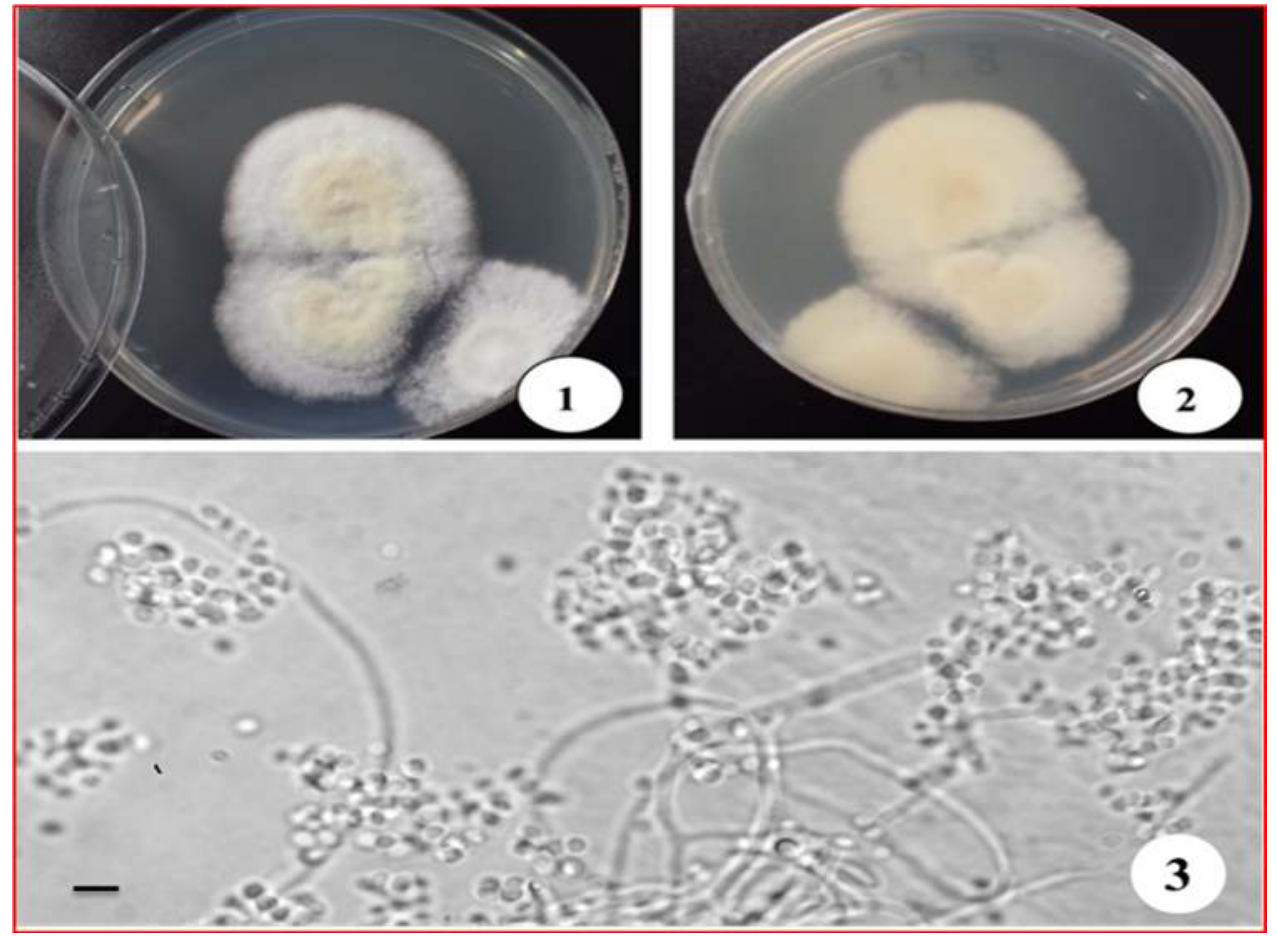

Figure 2. Beauveria pseudobassiana (isolate B3) grown on PDA.

1-Colony and aerial hyphae top view; 2- Colony and aerial hyphae bottom view;

3- conidia clusters (zigzag shape) scale bars $=5 \mu \mathrm{m}$.

Material examined: Iraq, Kurdistan region, Duhok; from soil samples collected under Rhus coriaria trees, Gara mountain, 10 June 2016, using selective media based on oat amended with CTAB and cyclohexamide. Living cultures in sterile water were deposited in Mycology bank, Department of plant protection, College of
Agricultural Engineering Sciences, University of Duhok, (BEG22), F.R. Hassan (Genbank MH374534).

\section{DISCUSSION}

The study of entomopathogenic fungi in Iraq is less developed with few works being published that they depend only on morphlogical charcteristics for identification. The new species record for Iraq reported 
that Beauveria pseudobassiana occurs in Gara Mountain soil along with other entomopathogenic fungi as $B$. bassiana, B. brongniartii, Paecilomyces farinosus (Assaf et al., 2011), Isaria javanica (Hassan et al., 2012) Metarhizium anisopliae (Abdullah et al., 2015) and $B$. varroae (Hassan et al., 2019).

B. pseudobassiana conidia are generally smaller than $B$. bassiana but it is indistinguishable from $B$. varroae, B. kipukae and B. australis, which also have globose/ subglobose/broadly ellipsoid conidia. Recently B. pseudobassiana is introduced by Rehner et al. (2011) as phylogenitically distant from $B$. bassiana but phenotypically is similar. Therefore their distribution and abundance might be not accurate and probably was identified in previous works as B. bassiana. Medo and Cagán̆ (2011), reported $B$ bassiana along with $B$. pseudobassiana as a common soil borne entomopathogens in Slovakia. They furthermore stated that $B$. bassiana predominate in arable soil whereas $B$. pseudobassiana was more abundant in forest soil. This is in line with our finding. The prevalence of $B$. pseudobassiana on hard tick, Ixodes ricinus (Acari: Ixodidae) was reported by Munteanu et al. (2014) from Moldova. The recovery percentage of $B$. pseudobassiana isolates from agricultural soil in Mexico was low comparable to high recovery percentage for $B$. bassiana as reported by Perez-Gonzales et al. (2014). Populations from hibernating pupae of Cameraria ohridella were found naturally infected with $B$. pseudobassiana in Slovakia (Schemmer et al., 2016). B. pseudobassiana was reported among the entomopathogens of Hypera postica (Gyllenhall) (Coleoptera: Curculionidae) in Turkey (Yucel et al., 2018).

The result of our study provides more information on the occurrence of indigenous Beauveria species in hibernation sites of sunn pest Eurygaster integriceps (Puton) in Iraq and the necessity to test their efficacy against insect pests.

Acknowledgements: The authors are thankful to Duhok Research Center/College of Veterinary Medicine, Duhok University, for providing the necessary lab facilities for this research work. Special thanks to Dr. Nacheervan Majeed Ghaffar for technical support in the laboratory, advices and tips on sequencing and phylogeny.

\section{REFERENCES}

Abdullah,S.K., R. A. Mustafa and L. H. Assaf (2015). Isolation of entomopathogenic and opportunistic fungi from soil in Duhok province,Kurdistan Region of Iraq by different selective isolation media. J. Biology, Agriculture and healthcare 5(4):73-79.

Agrawal,Y., P Mual and B. D. Shenoy (2014). Multigene genealogies reveal cryptic species
Beauveria rudraprayagi sp.nov. from India. Mycosphere 5:719-736

Alvarez-Baz,G., M. Fernandez-Bravo, J Pajares and E. Quesada-Moraga (2015). Potential of native Beauveria pseudobassiana strain for biological control of pine wood nematode vector Monochamus galloprovincialis. J. Invertebrate Pathology 132:48-56.

Ariyawansa, H.A., K. D. Hyde, S.C. Jayasiri, B. Buyck, W.T.C. Kandawatte, et al. (2015). Fungal diversity notes 111-252-Taxonomic and phylogenetic contributions to fungal taxa. Fungal Diversity 75: 1-248.

Assaf, L. H. (2007). Ecological study and evaluation of activity of Beauvaria bassiana (Bals.) Vuill and Paecilomyces farinosus (Dicks ex Fr.) on some biological aspects of sunn pest on wheat (Ph.D thesis). University of Mosul, College of Agriculture and Forestry, Iraq, 231pp. (In Arabic).

Assaf, L. H., R.A Haleem and S. K. Abdullah (2011). Association of entomopathogenic and other opportunistic fungi with insects in dormant locations. Jordan J. Biological Sciences 4:87-92.

Bedini, S., S. Sarrocco R. Baroncelli Vannacci and B. GandConti (2018). Pathogenic potential of Beauveria pseudobassiana as bioinsecticide in protein baits for the control of the medfly Ceratitis capitata. Bulletin of Insectology 7: 3138.

Chen, M. J., B. Huang, Z. Z. Li and J. W. Spatafora (2013). Morphological and genetic characterization of Beauveria sinensissp. nov. from China. Mycotaxon 124:301-308.

Chen, W-H., M. Li, Z-X. Huang, G-M. Yang, Y-F. Han, J-D. Liang and. Z-Q. liang (2018). Beauveria majiangensis, a new entomopathogenic fungus from Guizhou, China. Phytotaxa 333:243-250.

Hassan, F.R., S. K. Abdullah and L. H. Assaf (2019). First record of Beauveria varroae from Iraq. Nova Hedwigia 108: 427-433.

Hassan, W.A., L. H. Assaf, and S. K. Abdullah (2012). Occurrence of entomopathogenic and other opportunistic fungi in soil collected from insect hibernation sites and evaluation of their entomopathogenic potential. Bull. Iraq nat.Hist.Mus. 12:19-27.

Imoulan, A., Y. Li., W-J. Wang, A. Elmeziane, and Y-J. Yao (2016a). New record of Beauveria pseudobassiana from Morocco.Mycotaxon 131:913-923.

Imoulan, A., H. J. Wu., W. L. Lu, Y. Li, B.B. Li, et al. (2016b) Beauveria medogensissp.nov., a new fungus of the entomopathogenic genus from China. J. Invertebr.Pathol. 139: 74-81. 
Imoulan, A., M. Hussain, P. M. Kirk, A. El meziane and Y-J. yao, (2017). Entomopathogenic fungus Beauveria; Host specificity, ecology and significance of morpho-molecular characterization in accurate taxonomic classification. J. Asia-Pacific Entomology 20:1204-1212.

Kepler RM, J.J. Luangsa-ard, N.L. Hywel-Jones, C.A. Quandt, G.H. Sung, et al. (2017). A phylogenetic-based nomenclature for Cordycipitaceae (Hypocreales) IMA Fungus 8: 335-353.

Kocacevik, S. (2015). Molecular characterization, virulence and horizontal transmission of Beauveria pseudobassiana from Dendroctonus micans (Kug.) (Coleoptera; Curculionidae). J. Applied Entomology 139:321-400.

Medo, J. and L. Cagán (2011). Factors affecting the occurrence of entomopathogenic fungi in soils of Slovakia as revealed using two methods. Biological Control 59: 200-208.

Medo, J., J. Michalko, J. Medova and L.Cagan (2016). Phylogenetic structure and habitat associations of Beauveria species isolated from soils in Slovakia. J. Invertebrate Pathology 140:46-50.

Meyling, N.V. and J. Eilenberg (2007). Ecology of the Entomopathogenic Fungi Beauveria bassiana and Metarhizium anisopliae in Temperate Agroecosystems: Potential for Conservation Biological Control. Biological Control, 43: 145155.

Meyling, N.V., M. Lubeck, E. P. Buckley, J. Eilenberg and S. A. Rehner (2009). Community composition, host range and genetic structure of the fungal entomopathogen Beauveria in adjoining agricultural and seminatural habitats. Molecular Ecology18: 1282-1293.

Munteanu, N. V., P. V. Mitkoyets, G. V. Mitini, A. Movila, Y. S. Tokarey and A. Leclerque (2014) Prevalence of Beauveria pseudobassiana among entomopathogenic fungi isolated from the hard tick, Ixodes ricinus. Ticks and Tick-borne Disease 5:641-648.

Pérez-González, V.H., A. W. Guzmán-Franco, R. Alatorre-Rosas, J. Hernández-Lópeza, A. Hernández-Lópezb, M. G. Carrillo- Beníteza and J. Baverstock (2014): Specific diversity of the entomopathogenic fungi Beauveria and Metarhiziumin Mexican agricultural soils. J. Invertebrate Pathology 119: 54-61.

Posadas, J.B., R. M. Comerio, J. I. Mini, A. L. Nussenbaum, and R. E. Lecuona, (2012). A novel dodine-free selective medium based on the use of cetyltrimethyl ammonium bromide (CTAB) to isolate Beauveria bassiana,
Metarhizium anisopliae sensolato and Paecilomyces lilacinus from soil. Mycologia .104:974-980.

Rehner, S. and E. Buckley (2005). A Beauveria phylogeny inferred from nuclear ITS and EF1- $\mathrm{D}$ sequences: Evidence for cryptic diversification and links to Cordyceps teleomorphs. Mycologia 97:84-98.

Rehner, S.A., A. M. Minnis, G-H. Sung, J. J. Luangsaard, L. Devotto and R. A. Humber (2011). Phylogeny and systematics of the anamorphic, entomopathogenic genus Beauveria. Mycologia 103:1055-1073.

Robène-Soustrade, I., E. Jouen, D. Pastou, M. PayetHoarau, , T. Goble, et.al. (2015). Description and phylogenetic placement of Beauveria hoplocheli sp. nov. used in the biological control of the sugarcane white grub, Hoplochelus marginalis, on Reunion Island. Mycologia107: 1221-1232.

Romon, P., H. Hatting, A Goldarazena and J.C. Iturrondobeitia (2017). Varriation in virulence of Beauveria bassiana and $B$. pseudobassiana to the pine weevil Pissoddes nemorensis in relation to mycelium characteristics and virulence genes. Fungal Biology 121:189-197.

Roy, H. E., F.E. Vega and D. Chandler (2010). The Ecology of Fungal Pathogens. Springer, The Netherlands,pp.240.

Schemmer, R., P. Chladekora, J. Medoand M. Barta (2016). Natural prevalence of entomopathogenic fungi in Hibernating pupae of Cameraria ohridella (Lepidoptera: Gracillariidae) and virulence of selected isolates. Plant. Protect. Sci. 52:199-208.

Tu, C.C and R. Krischner (2014). ITS barcodes for Beauveria bassiana in Taiwan. Fung.Sci. 29:3341.

White, T., T. Bruns, S. Lee and J. Taylor (1990). Amplification and direct sequencing of fungal ribosomal RNA genes for phylogenetics. Inn; Innis,M., Gelfond, D., Shinsky,I and White,T.(eds.): PCR protocols: A guide to methods and applications;p.315-322.Academic Press,New York.

Yucel, B., C. Gozuacik, D. Gencer, I. Demirand Z. demirbag (2018). Determination of fungal pathogens of Hyperia postica (Gyllenhall) (Coleoptera:Curculionidae): isolation, characterization, and susceptibility. Egyptian J. Biological Pest Control.28:39.

Zhang, S.L., L. M. He, ,C X. hen and B. Hueng, (2012). Beauveria lii sp.nov.isolated from Henosepilana vigintioctopunctata. Mycotaxon121:199-206. 